\title{
EL BACHILLERATO EN LA DICTADURA DE PRIMO DE RIVERA: EL DEBATE CALLEJO-SAINZ RODRÍGUEZ
}

\section{BACCALAUREATE IN THE DICTATORSHIP OF PRIMO DE RIVERA: THE DEBATE BETWEEN CALLEJO AND SAINZ RODRÍGUEZ}

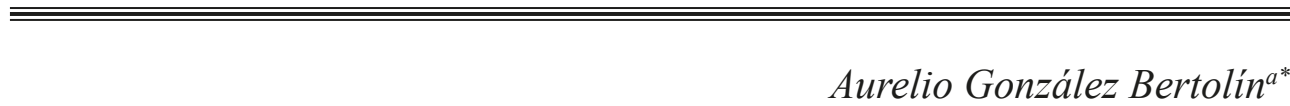

Fechas de recepción y aceptación: 6 de noviembre de 2019, 2 de marzo de 2020

DOI: 10.46583/edetania_2020.57.509

Resumen: La experiencia de la dictadura de Primo de Rivera precipitó la llegada al poder, como apoyo doctrinal del primorriverismo, de unas nuevas élites políticas provenientes del catolicismo social, del tradicionalismo y de las juventudes mauristas. Esta nueva derecha autoritaria desempeñó un papel relevante en el origen y desarrollo de movimientos posteriores como Acción Española y la CEDA (Confederación Española de Derechas Autónomas), y estuvo presente con posterioridad en los distintos grupos que concurrieron en la política institucional del franquismo.

De igual modo, el debate público e institucional en torno al Plan Callejo propició la configuración de dos modelos de bachillerato propios de la derecha española, clásico uno y ecléctico el otro, que fueron alternando en la política educativa española hasta la Ley General de Educación de 1970. El primero inspiró la Ley de Bases de Sainz Rodríguez de 1938, y el segundo estuvo en el origen de la reforma del bachillerato de Ruiz-Giménez de 1953.

Palabras clave: Enseñanza Media, Bachillerato, dictadura de Primo de Rivera, Plan Callejo. Mártir.

${ }^{a}$ Facultad de Magisterio y Ciencias de la Educación. Universidad Católica de Valencia San Vicente

* Correspondencia: Universidad Católica de Valencia San Vicente Mártir. Facultad de Magisterio y Ciencias de la Educación. Calle Sagrado Corazón 5. 46110 (Godella), Valencia. España.

E-mail: aurelio.gonzalez@ucv.es 
Abstract: The experience of the dictatorship of Primo de Rivera precipitated the arrival to power, as a doctrinal support of primorriverism, of new political elites coming from social Catholicism, traditionalism and Maurism youths. This new authoritarian right-wing movement played an important role in the origin and development of later movements like Acción Española and CEDA (Spanish Confederation of Autonomous Right); and it was present later in the different groups that participated in the institutional politics of the Franco regime. Similarly, the public and institutional debate surrounding Callejo Plan contributed to the configuration of two secondary school models of the Spanish right-wing politics, one classical and one ecclectical, which alternated in the Spanish educational policy up to the General Education Act of 1970.

The first one inspired the law of Bases by Sainz Rodríguez in 1938, and the second one was in the origin of the reform of the Baccalaureate title by Ruiz-Giménez in 1953.

Keywords: Secondary Education, Baccalaureate, Primo de Rivera dictatorship, Callejo Plan.

\section{En torno a la dictadura de Primo de Rivera}

El 13 de septiembre de 1923 el capitán general de Cataluña, Miguel Primo de Rivera, se sublevó - contando con la inhibición de Alfonso XIII- contra el Gobierno de la nación presidido por García Prieto. Mediante un manifiesto hecho público ese mismo día, en nombre del ejército y reclamándose intérprete del supuesto sentir mayoritario del país, hacía responsables a los ministros y al Parlamento del desgobierno, la perturbación social y la amenaza separatista que habían llevado a España a una situación insostenible. "No venimos a llorar lástimas y vergüenzas, sino a ponerlas pronto y radical remedio, para lo que requerimos el concurso de todos los buenos ciudadanos", dijo (Primo de Rivera, 1923, p. 1). Primo de Rivera se daba un plazo de noventa días -como las letras de cambio, según afirmó él mismo- para imprimir un cambio de rumbo al Gobierno de la nación,

Para ello (...) se constituirá en Madrid un Directorio inspector militar con carácter provisional, encargado de mantener el orden público y asegurar el funcionamiento normal de los ministerios y organismos oficiales, requiriendo al país para que en breve plazo nos ofrezca hombres rectos, sabios, laboriosos y probos, que puedan constituir ministerio a nuestro amparo (Primo de Rivera, 1923, p. 1). 
La sociedad española de los años veinte recibió con pasividad, expectación y discreta complacencia el advenimiento del nuevo directorio pretoriano. Las clases acomodadas, incluyendo las burguesías periféricas de Cataluña y el País Vasco -estudios recientes inciden en el auge del nacionalismo vasco y, sobre todo, el catalán en los años previos al pronunciamiento (Lopez de Íñiguez, 2015)-, vieron en Primo de Rivera al cirujano de hierro costista capaz de regenerar el sistema político y garantizar sus intereses económicos. La opinión conservadora también apoyó explícitamente a quien consideraba el hombre providencial para llevar a cabo el "saneamiento moral del país", el diario El Debate, referente del catolicismo político de la época, se puso inmediatamente de parte de los militares como símbolo del verdadero sentimiento nacional (Morales, 2018). Y el socialismo, que en un principio mantuvo una actitud de reserva, terminó por colaborar abiertamente con el régimen (López Martín, 1994). Por tanto, la oposición al pronunciamiento quedó reducida a las manifestaciones de repulsa de anarquistas y comunistas que, en cualquier caso, no obtuvieron respuesta popular (Barrio, 2004). Cabe recordar que incluso "Sobre la vieja política", el primer articulo publicado por Ortega y Gasset en el diario El Sol después de la proclama de Primo de Rivera, ha sido considerado como testimonio de adhesión al nuevo régimen o, al menos, como una actitud de benevolente expectativa (Fonck, 2010).

Miguel Primo de Rivera y Orbaneja, segundo marqués de Estella, era un prestigioso militar de trayectoria liberal y valor probado en las campañas de Cuba, Filipinas y Marruecos. Intuitivo y brillante a su manera, este aristócrata jerezano era un caballero paternalista, campechano y no muy leído, que probablemente carecía de la más elemental urdimbre ideológica en la que fundamentar su actuación política. Tusell (1974: 451) ha señalado que Primo de Rivera, en realidad, "no hacía otra cosa que elevar a la categoría de gobierno lo que los españoles de su tiempo hablaban en las charlas de café".

La dictadura supuso la ocupación del Gobierno y de la Administración por parte del ejército, pero también "el ascenso de las nuevas élites políticas derechistas provenientes del catolicismo social, del tradicionalismo y del maurismo, en cuyo horizonte ideológico y mental latía el rechazo de la tradición liberal" (González Cuevas, 2005: 100). Raúl Morodo, en su ya clásico trabajo sobre Acción Española aludía a tres corrientes: “el tradicionalismo, la corriente católico-social y el maurismo o conservadurismo clásico que 
constituyeron el punto de apoyo, en cuanto punto de partida doctrinal que asume la dictadura" (Morodo, 1980, p. 11) y que definieron de una manera explícita o implícita la obra primorriverista.

Conforme a la opinión de otros autores (Payne, 1984; Gómez Navarro, 1991; González Calleja, 2005; Avilés, 2017; Giménez, 2018) la dictadura de Primo de Rivera no solo ocasionó la desaparición del modelo de la Restauración, basado en el turno de partidos, sino que propició el nacimiento de una nueva derecha, ya que precipitó la escisión ideológica entre una derecha fiel a los procedimientos liberal-parlamentarios y otra de corte netamente autoritario. La primera desapareció de la escena política hasta la transición democrática, pero la segunda estuvo presente en el origen de los grandes movimientos de la derecha autoritaria del siglo, tales como Acción Española, la CEDA (Confederación Española de Derechas Autónomas) e, incluso, FET y JONS (Falange Española Tradicionalista y de las Juntas de Ofensiva Nacional Sindicalista).

El nuevo tradicionalismo español, formulado por Vázquez de Mella y, sobre todo, por su discípulo Víctor Pradera, recogía y trataba de actualizar los arcaicos principios doctrinales del carlismo, si bien, a diferencia de este, no hacía cuestión del pleito dinástico. El tradicionalismo de los primeros años veinte defendía un marco ideológico basado en la monarquía tradicional, la unidad de la patria -aunque compatible con el foralismo y el desarrollo regional-, el corporativismo social y la apología del golpe de Estado militar. Para los nuevos tradicionalistas, como Pradera o Maeztu, el catolicismo debía desempeñar un papel de capital importancia en los ámbitos político y social, ya que a él correspondía ser el gran inspirador del orden, la coherencia social y la estabilidad del sistema político.

Por su parte, el catolicismo político -heredero en primer grado de la corriente católico-social a la que aludía Morodo- se conformó a partir de una nueva teoría política cristiana basada, precisamente, en la doctrina social pontificia. De especial trascendencia fue la creación en 1909, por el jesuita Ángel Ayala, de la ACN de P (Asociación Católica Nacional de Propagandistas). El objetivo fundamental de la Asociación -en origen denominada Asociación Católica de Jóvenes Propagandistas- era la formación de cuadros selectos que tuviesen capacidad para influir en la vida pública conforme a los principios sociales y políticos del catolicismo. En los primeros tiempos ya comen- 
zaron a destacar hombres como José María Gil-Robles, los hermanos Martín Artajo, Martín-Sánchez o el propio Ángel Herrera Oria, seglar a la sazón, que desempeñarían un papel relevante en los años posteriores.

Al doblar la segunda década del siglo xx, amplios sectores provenientes del catolicismo social y de la propia Acción Católica se hallaban inmersos en la creación y consolidación del denominado PSP (Partido Social Popular). Este grupo ha sido considerado por muchos como el primer intento de configurar una organización política demócratacristiana en España (Álzaga, 1973; Tusell, 1974; Barba, 2001; Cuenca, 2003). Sin embargo, con el advenimiento de la dictadura, el entorno de Ángel Herrera Oria participó activamente en la política del primorriverismo a través de las denominadas Uniones Patrióticas.

Por último, los grupos y personas provenientes de las Juventudes Mauristas de la primera década del siglo xx constituyeron, a juicio de González Cuevas (2005, p. 61), "la manifestación española más próxima al paradigma de la derecha radical moderna". Morodo, como hemos visto más arriba, utilizaba el término maurismo como equivalente a conservadurismo clásico. Lo cierto es que los líderes formados en la organización juvenil del maurismo, como Antonio Goicoechea o José Calvo-Sotelo -los viejos líderes mauristas de la Restauración nunca se avinieron a participar en la dictadura-, propugnaban un nuevo tipo de democracia orgánica y conservadora que propiciase el aumento del poder estatal en la sociedad civil. El Estado debía participar en el desarrollo económico general fomentando la iniciativa privada y garantizando el proteccionismo sobre la producción nacional. De hecho Primo de Rivera, durante el denominado Directorio Civil, reclamó la colaboración de los nuevos cuadros políticos formados en el maurismo para mejorar la eficacia del aparato estatal.

Tusell atribuye a la acción política de estos diversos grupos la evolución institucional de la dictadura, que pasó de proclamarse como un Gobierno regeneracionista de carácter transitorio a tratar de consolidar un régimen autoritario con voluntad de permanencia:

Un primer grupo de católicos procedentes del PSP, el maurismo, el tradicionalismo o el sindicalismo cristiano colaboró activamente con la Dictadura desde el comienzo hasta el fin y poco a poco convirtió a ésta, de forma transitoria de gobierno destinada a llevar a cabo la regeneración anticaciquil del país, en sistema ideal de gobierno con carácter perenne (Tusell, 1974, p. 120). 
Así pues, Primo de Rivera quizá no, pero el primorriverismo sí tenia ideología. O mejor dicho, propició la concurrencia en el poder, como apoyo doctrinal de la propia dictadura, de sectores ideologicos nítidamente definidos y perfectamente identificables a lo largo de la historia política de la mayor parte del siglo XX.

\section{La EdUCACIÓN EN LA EsPAÑA DE 1920}

En la España de 1920, con un censo de algo más de veintiún millones de habitantes, el 52,35 \% de la población no sabía leer ni escribir (López Martín, 1994). Es decir, casi once millones de españoles eran iletrados de solemnidad. En el curso académico de 1920-21 se matricularon en Bachillerato 52.288 alumnos, de los cuales únicamente 5.067 eran mujeres. Algo menos de un tercio del total, 16.521, lo hizo en los institutos oficiales del Estado. En 1920 había en España 58 institutos de Enseñanza Media, por 215 colegios privados dedicados a este mismo grado, la mayoría de ellos regentados por órdenes religiosas.

El plan vigente al entrar en la segunda década del siglo era el establecido por un Real Decreto de 6 de septiembre de 1903, durante la gestión ministerial de Gabino Bugallal. Se trataba, por tanto, de una normativa de inusitada longevidad para lo acostumbrado en la Enseñanza Media española. El popularmente conocido como "Plan del 3" seguía fielmente la dirección marcada por las reformas del conservador García Alix en 1900 -primer titular del nuevo Ministerio de Instrucción Pública- y, sobre todo, del conde de Romanones en 1901.

Tanto el "Plan del 3" como los dos anteriores partían de la necesidad de regular la segunda enseñanza mediante una normativa general basada en el consenso de los partidos políticos. Se establecía un Bachillerato único, de seis cursos de duración y con pocas asignaturas. Los objetivos fundamentales de estas reformas podrían resumirse en dos: en primer lugar, conciliar los estudios clásicos y los técnicos; y en segundo, aunque no menos importante, potenciar -enaltecer, se decía- la enseñanza oficial.

Para esto último se contemplaba una serie de medidas, como mejorar la inspección, intensificar el control sobre la enseñanza privada y exigir la ti- 
tulación oficial al profesorado de toda clase de centros, tanto estatales como privados. Asimismo se adoptó un sistema de exámenes sumamente favorable para el alumnado oficial. Mientras que los estudiantes de los institutos estatales se examinaban ante un tribunal constituido por sus propios profesores, los alumnos de los colegios privados debían examinarse en los institutos, ante un tribunal compuesto por catedráticos de segunda enseñanza y por un profesor del alumno, con titulación adecuada de licenciado o doctor, que participaba en el tribunal con voz pero sin voto. Es decir, las denominadas reválidas.

\section{El dictamen del Consejo de Instrucción Pública sobre la reforma} DE LA SEgunda ENSEÑANZA

Inmediatamente después del pronunciamiento militar del 13 de septiembre, Primo de Rivera solicitó del Consejo de Instrucción Pública un dictamen sobre la reforma de la Segunda Enseñanza. Desde su institucionalización en el primer tercio del siglo XIX, este tramo del sistema educativo, aunque cursado por una selecta minoría de la población -o quizá por ello-, se convirtió en campo de batalla político e ideológico del sistema educativo. Todo régimen, tendencia o partido que llegaba al poder tenía entre sus prioridades implantar un nuevo plan de segunda enseñanza y derogar el anterior, que era el de su adversario político (González Bertolín, 2015).

En el caso que nos ocupa, según consta en el acta de la sesión extraordinaria de este órgano consultivo celebrada el 21 de enero de 1924. A la sesión asistió el propio Primo de Rivera, acompañado del subsecretario de despacho del Ministerio, Francisco Javier García de Lara, que no habiéndose nombrado ministro del Directorio era el máximo responsable del departamento.

En consecuencia, a comienzos de 1924 se hizo público el dictamen del Consejo. Importa mucho señalar que el Consejo de Instrucción Pública que llegó a la dictadura era fruto de la remodelación efectuada por César Silió, ministro de Instrucción Pública del Gobierno de Maura de 1921. Esta drástica reforma, llevada a cabo por un hombre cercano a Goicoechea y Calvo Sotelo, consiguió mejorar la organización, los procedimientos técnicos y la operatividad del Consejo; sin embargo imprimió un sesgo partidista al órgano consultivo al propiciar la elección de consejeros de marcado perfil maurista. 
De hecho, pocos días antes de conocerse el dictamen, el 23 de febrero de 1924, la Revista España publicó un artículo de Manuel Azaña en el que lamentaba que el Gobierno de García Prieto, con el liberal Joaquín Salvatella en la cartera de Instrucción Pública, no hubiese llevado a cabo una remodelación a fondo de los miembros del Consejo:

El Consejo de Instrucción Pública discute en estos momentos la próxima reorganización de la enseñanza en España (...) Consejo que los liberales dejaron intacto en su último e inolvidable periodo de mando. Se proponían sin duda reformarlo un año cualquiera. La muerte les sorprendió como a muchos pecadores resolviendo planes para enmendar su vida. No conocemos el pormenor de los dictámenes que el Consejo emite; pero sí el pensamiento de la mayoría que los propone (Azaña, 1923, p. 325).

Pues vayamos a los pormenores del dictamen (Ceprián, 1991, p. 468-481). El documento comenzaba su andadura de catorce folios tratando de fijar el carácter de la Enseñanza Secundaria que, "como continuación de la Enseñanza Primaria", debía aspirar a:

a) disponer al individuo para la vida nacional, social y humana; b) a favorecer el desarrollo pleno de todas las actividades del adolescente en el orden físico, intelectual y moral, buscando con ahínco los medios de fomentar en la juventud hombres de carácter y responsabilidad moral; c) preparar las inteligencias para el cultivo de los estudios superiores, ya de orden liberal, ya profesional.

Se proponía un plan de estudios distribuido en siete cursos. Un periodo común de cuatro años "como desenvolvimiento progresivo de la Enseñanza Primaria"; y otro superior de tres años, dedicado al razonamiento y sistematización de lo anteriormente estudiado "por vía principalmente inductiva". En este último periodo de tres años el Bachillerato se bifurcaría en dos secciones fundamentales: letras y ciencias -por este orden en el documento-; además se contemplaba una tercera opción: el denominado Bachillerato profesional o politécnico, "que a parte de su propio fin para las Escuelas Técnicas", también habilitaría, cumplidos los demás requisitos generales, para el acceso a carreras universitarias. Asimismo, el Consejo recomendaba que el Bachillerato fuese necesario para el ingreso en el mayor número de centros docentes y cuerpos del Estado. 
En opinión del Consejo de Instrucción Pública los alumnos de Bachillerato debían pasar de curso mediante las calificaciones dadas por sus propios profesores. Al finalizar los siete años se realizaría un examen para la obtención del título ante un tribunal compuesto por cinco miembros: un catedrático de universidad, tres catedráticos de instituto y un titulado ajeno a la enseñanza estatal. Para los alumnos de la enseñanza privada se contemplaba, además del ejercicio anterior, un examen intermedio al finalizar el cuarto año. El tribunal para este ejercicio estaría compuesto por tres catedráticos de instituto y dos profesores de la enseñanza privada.

El plan de estudios pretendía conciliar los estudios clásicos y científicos. Se proponía que estuviese conformado por las siguientes asignaturas: Lengua y Literatura española, Matemáticas, Lengua Latina, Ciencias Naturales, Física y Química, Filosofía y Derecho, Geografía e Historia, Lengua francesa, Religión, Dibujo, Lengua Griega para los alumnos de letras e Inglés o Alemán para los de ciencias.

Según el dictamen del Consejo, "al lado" de la enseñanza oficial del Estado debía admitirse la llamada a la sazón "enseñanza colegiada", por ser esta "la única manifestación de la libertad de enseñanza" que ofrecía garantías de idoneidad. Con respecto a la enseñanza libre, se afirmaba que era "perjudicial para la patria porque favorece el autodidactismo" y era contraria a la verdadera educación intelectual: se proponía la supresión de esta clase de enseñanza, si bien de manera gradual y tratando de facilitar la asistencia a los institutos de los estudiantes que en aquellos momentos la cursaban.

Los colegios privados, además de contar con las instalaciones y medios materiales adecuados, debían acreditar la competencia pedagógica de su director y profesores. Por consiguiente, el dictamen mencionaba la conveniencia de exigir al profesorado de la enseñanza colegiada el título de licenciado o doctor en Filosofía y Letras o Ciencias.

En realidad, lo que prescribía el documento del Consejo con respecto a la enseñanza colegiada era una "tutela" de los colegios privados -denominados "colegios incorporados"- por parte del instituto del Estado al que estuviesen adscritos. Asimismo el Consejo consideraba imprescindible -"en relación con la libertad que en este proyecto se otorga a la enseñanza colegiada"- la creación de la Inspección de Segunda Enseñanza. Esta institución, de carácter eminentemente pedagógico y colaborativo -"y de consejo", se decía en el 
documento-, tendría como misión fundamental la de tutelar a los institutos y colegios, corrigiendo las deficiencias que pudieran producirse y procurando en todo momento "excitar el amor a la obra trascendental de la cultura y la educación".

Las últimas consideraciones del dictamen hacían alusión a la cuestión económica. Se advertía de que la implantación del plan objeto del informe requería mayores recursos económicos. El documento finalizaba señalando la urgencia de mejorar las instalaciones de los institutos y dignificar la retribución del profesorado:

Locales en condiciones que no sean, como muchos de los actuales, bochorno para un país medianamente organizado; dotación del profesorado, que le permita una vida por completo entregada a su misión; material, etc., son elementos indispensables si nuestra Patria aspira a ser considerada como una Nación culta (Ceprián, 1991, p. 481).

4. La impopularidad del Plan Callejo. Debate en la Asamblea NaCiOnAl CONSUltiva

A partir de septiembre de 1925 -en este mes se produjo el desembarco de Alhucemas-, el Directorio de Primo de Rivera alcanzó sus mayores cotas de popularidad y prestigio político como consecuencia de la recuperación económica y las victorias sobre las cábilas de Abd el-Krim en la campaña militar del Rif. A partir de entonces Primo de Rivera, que siempre había afirmado el carácter provisional de su gobierno - la letra a noventa días-, tuvo la tentación de aprovechar la coyuntura favorable para consolidar su permanencia en el poder.

Para tal fin licenció a los generales que le habían acompañado en el Directorio militar y nombró un gobierno de "hombres civiles" -el denominado Directorio Civil-, la mayoría de ellos provenientes del mundo profesional y vinculados políticamente a sectores emergentes de la derecha conservadora. Parece ser que Alfonso XIII transigió con esta maniobra institucionalizadora a condición de que en plazo breve el país pudiera contar con leyes que constituyan el fundamento de su normalidad. 
El nuevo ministro de Instrucción Pública del Directorio Civil, Eduardo Callejo de la Cuesta, era un catedrático vallisoletano, nacido en 1875, con escasa experiencia política, si bien había contribuido activamente a la organización de las Uniones Patrióticas de Castilla la Vieja. La Unión Patriótica, que acabaría convirtiéndose en el partido oficialista del primorriverismo, surgió en un principio, según afirma Tusell (1974, p. 461), “espontáneamente en los círculos de catolicismo político que veían en la desaparición del parlamentarismo caciquil una ocasión óptima para llevar a cabo su versión particular de la regeneración". Interesa señalar que Eduardo Callejo fue, junto al presidente de la ACN de P. Ángel Herrera Oria, una de las ciento veinte personas que constituyeron la Unión Patriótica Castellana tras un acto celebrado el 30 de septiembre de 1923 en el Teatro Calderón de Valladolid.

Para el cargo de director general de Enseñanza Superior y Secundaria fue designado el joven profesor universitario, de treinta y cinco años, Wenceslao González Oliveros, catedrático de Filosofía del Derecho en La Laguna, que andando el tiempo sería primer gobernador civil de Barcelona en el franquismo y procurador a Cortes en varias legislaturas durante los años cuarenta y cincuenta. De hecho, González Oliveros fue uno de los miembros de la Comisión de Enseñanza de las Cortes españolas que debatió la Ley de Ordenación de la Enseñanza Media de 1953, y aprovechó su intervención para hacer una loa de la Ley Ruiz-Giménez y, de paso, reclamarla deudora, veinticinco años después, del Plan Callejo (González Bertolín y Sanz, 2018).

Pero vayamos al Plan Callejo. Pese a que en el preámbulo del Real Decreto se decía haber tenido en cuenta "algunas de las orientaciones consignadas por el Consejo de Instrucción Pública en su luminoso y razonado informe”, lo cierto es que el legislador hizo caso omiso del dictamen evacuado por órgano consultivo del Ministerio.

En primer lugar, la reforma Callejo trató de resolver una de las polémicas educativas del tiempo, adoptando para ello una fórmula intermedia entre el Bachillerato clásico y el realista; si bien, conforme al discurso modernizador de los gobiernos de la dictadura, propició una mayor presencia curricular de las materias de carácter técnico y científico. A continuación se afirmaba la sustantividad propia del Bachillerato, que no solo debía ser, según los casos, complemento de la Primaria o preparación para la Universidad, sino que constituía la formación apropiada para otros estudiantes, como aquellos que se 
encaminasen a escuelas especiales civiles o militares, los que aspirasen a ingresar en determinadas escalas del funcionariado estatal y "para gran número de señoritas que asisten a los institutos".

Conforme al artículo $1 .^{\circ}$ se establecía un Bachillerato de seis años, dividido en dos periodos: el Bachillerato elemental, de tres cursos, encaminado a perfeccionar la cultura general adquirida en la instrucción primaria; y el Bachillerato universitario, también de tres cursos, preparatorio para el acceso a la enseñanza superior. Este último tenía un primer curso común, dividiéndose a partir del segundo año en ciencias y letras.

El nuevo Bachillerato se desmarcaba claramente del modelo cíclico propuesto en el dictamen del Consejo de Instrucción Pública. El método cíclico, generalmente aceptado en la época desde distintas ideologías y planteamientos pedagógicos, consistía en el estudio de un mismo grupo de materias formativas durante varios años consecutivos, ampliando progresivamente la extensión de los programas y el nivel de exigencia a los alumnos.

Con objeto de reducir el número de exámenes se estableció un nuevo sistema para la calificación de los estudiantes. Todos los alumnos de Bachillerato elemental, oficiales y no oficiales, podían elegir entre efectuar los ejercicios por grupos de asignaturas o realizar una prueba final de conjunto. En ambos casos los exámenes tendrían lugar en el instituto oficial, ante un tribunal compuesto por tres catedráticos de Enseñanza Media.

Con respecto al Bachillerato superior, todos los alumnos, tanto los oficiales como los de la enseñanza colegiada, tenían que verificar un examen final de conjunto que se celebraría en la Universidad, ante un tribunal compuesto por tres catedráticos de la facultad a la que optase el examinando, un catedrático de instituto de Enseñanza Media de la capital correspondiente y un licenciado o doctor ajeno a la enseñanza oficial.

La reforma Callejo, polémica y controvertida desde un principio, terminó por convertirse en decididamente impopular entre los españoles de su tiempo. Ahora bien, en nuestra opinión, la mala prensa de la reforma se debió más a causas políticas y administrativas que a razones estrictamente educativas. El ministro Callejo, sin duda imbuido del afán reformista y modernizador del que el propio Primo de Rivera era máximo acicate, decidió implantar el nuevo Bachillerato de golpe, soslayando cualquier clase de medida gradual o periodo transitorio. Esta rigidez administrativa generó una abundante ca- 
suística, no prevista en un principio, conforme a la cual muchos estudiantes de bachillerato se sintieron perjudicados por las condiciones de adaptación al nuevo plan.

Parece ser que los directores de los institutos tampoco extremaron el celo en resolver los casos particulares que se presentaron en sus respectivas jurisdicciones, contribuyendo a crear malestar entre los padres y una cierta alarma social por la ambigua situación administrativa de no pocos estudiantes.

En el plano político, el debate sobre la reforma Callejo tuvo lugar en la sesión inaugural de la Asamblea Nacional Consultiva de la dictadura celebrada el 29 de octubre de 1927. El proyecto de creación de la Asamblea Nacional supuso el paso definitivo de un gobierno provisional regeneracionista a un régimen autoritario con aspiraciones de permanencia en el poder. De hecho, este fue el momento en el que algunos sectores sociales y políticos, que en un principio eran colaboracionistas o cuanto menos permisivos, se desmarcaron del rumbo emprendido por la dictadura de Primo de Rivera. La Asamblea quedó conformada por cuatrocientos asambleístas, la mayoría de ellos de extracción corporativa y elección, franca o solapada según los casos, estrictamente gubernamental. Los diez asambleístas pertenecientes al PSOE (Partido Socialista Obrero Español) y a la UGT (Unión General de Trabajadores), siguiendo las tesis de Indalecio Prieto, decidieron renunciar a sus escaños en la Asamblea.

Así las cosas, la única oposición, siquiera testimonial, presente en la Cámara se limitó a un exiguo grupo de monárquicos alfonsinos que recelaban, como el propio Alfonso XIII, de las maniobras institucionalizadoras de Primo de Rivera. Uno de ellos, Pedro Sainz Rodríguez, que era un joven y brillante catedrático de la Universidad Central, solicitó que en el orden del día correspondiente a la primera sesión de la Asamblea se incluyese una interpelación sobre la reforma de la segunda enseñanza efectuada por el Ministerio de Instrucción Pública.

Sainz Rodríguez, según dejó dicho en sus memorias, había recibido de Alfonso XIII el encargo de actuar en la Asamblea como si fuese diputado de oposición en un parlamento plural. Lo cierto es que preparó una interpelación de verdad; dura y corrosiva, "a la inglesa", como se decía entonces, con la que consiguió dar un auténtico revolcón parlamentario a Eduardo Callejo, hasta el punto de que el propio Primo de Rivera tuvo que salir a la tribuna de oradores 
para intervenir en defensa de su ministro. Así explicaba Sainz Rodríguez en sus memorias la estrategia de aquel discurso:

Me di perfecta cuenta de que, en una asamblea de funcionarios nombrada por el Gobierno, era inútil provocar una reacción que diera lugar a una votación adversa y por eso busqué el que la votación se hiciera de facto, provocando la risa con mis comentarios a los disparates del Plan Callejo (Sainz Rodríguez, 1978, p. 95).

Pero vayamos al Diario de Sesiones de la Asamblea Nacional (29/10/1927, p. 16-26) para tratar de identificar esos disparates que Sainz Rodríguez atribuía al Bachillerato de Callejo en sus intervenciones durante el Debate de la Asamblea Nacional Consultiva sobre la adaptación del nuevo plan de Bachillerato. Sainz Rodríguez inició su turno de palabra con la intención de dejar sentado el carácter estrictamente técnico de su intervención, señalando, además, que la reforma defendida por Callejo carecía de una ideología doctrinal que la sustentase. Consecuentemente inició su intervención aludiendo a las características curriculares del plan: supresión de la gramática -“que impediría el cultivo de la lengua común de los españoles”-, así como un pobre tratamiento de las matemáticas, los idiomas extranjeros, la historia nacional y la religión.

Parece evidente que Sainz Rodríguez, cuando reprobaba el nuevo plan de estudios, tenía en el magín, como término de comparación para efectuar su crítica, un modelo clásico de bachillerato. A continuación, trató de ridiculizar el criterio con el que se habían desdoblado y ordenado en el plan de estudios algunas asignaturas fundamentales:

La Historia de España se estudia después de la Historia de América. Cosa ésta peregrina, cuya explicación no he podido encontrar. Pensando en ello, he llegado a creer que el Ministerio, por un rasgo de galantería hispanoamericana, ha pretendido que los alumnos españoles se enteren de la historia del mundo por el mismo camino que siguieron los indios americanos cuando a éstos los descubrió Colón.

En lo que tocaba a la estructura del plan, Sainz Rodríguez habló de la bifurcación en letras y ciencias, que provocaba, en su opinión, una decantación 
vocacional prematura e irreversible de los estudiantes. Se refirió a continuación al sistema de examen por grupos de asignaturas. Esta innovación, que al parecer tenía la loable intención de reducir el número de exámenes, era, según el interpelante, totalmente incompatible con la multiplicidad de asignaturas prevista en el plan de estudios. A juicio de Sainz Rodríguez el examen por grupo de asignaturas solo era viable cuando estaba precedido por una enseñanza cíclica.

Sainz Rodríguez abordó la recta final de su discurso responsabilizando al Ministerio de Instrucción Pública -como no podía ser de otra manera- de todas y cada una de las incongruencias del nuevo plan. Y terminó hablando de los perjuicios que había ocasionado a los estudiantes y sus familias la implantación automática del nuevo Bachillerato. Este era, al fin y al cabo, el objeto formal de su interpelación, gracias al cual, según Sainz Rodríguez, habían salido a la luz pública todas las demás incongruencias y defectos de la reforma de Callejo.

Callejo acometió su turno precisando que el nuevo plan de estudios ni había caído en "aerolito", ni se lo había sacado de su "propia Minerva", sino que se había llevado a cabo después de analizar los antecedentes, "con grandes vigilias y estudios", escuchar la voz de los expertos y elaborar los preceptivos informes por parte del Ministerio. Defendió el carácter "ecléctico" de su bachillerato, situándolo en un punto intermedio entre un modelo clásico y humanístico y otro realista, tecnificado y utilitario; si bien admitió que, precisamente por su carácter innovador tenía algún pequeño inconveniente derivado de su adaptación, pero presentaba a cambio múltiples ventajas y "adelantos", como la intensificación del estudio de las lenguas vivas con "tres años de francés que pueden bastar para manejarse en la vida", el incremento del estudio práctico de materias como la lengua o las matemáticas, y la incorporación de materias como taquigrafía y mecanografía.

Defendió la bifurcación del bachillerato que, efectivamente, era una opción que ya había sido adoptada a finales del siglo xIX por diversos países europeos -también la multiplicidad de bachilleres: clásico, realista, técnico...con el fin de dar respuesta a las nuevas necesidades sociales y demandas económicas: Y, por último, Callejo atribuyó las dificultades de adaptación al nuevo plan a dos causas ajenas a las normas transitorias y, por tanto, extrañas a su gestión ministerial en este asunto. En primer lugar, a la irresponsabilidad 
de un crecido número de estudiantes, "centenares de alumnos", que se matriculaban cada ejercicio de asignaturas sueltas correspondientes a un nuevo curso sin haber aprobado todavía las de los años anteriores. En segundo lugar, a la "desgana y la poca voluntad de los institutos" en el cumplimiento y aplicación de las reglas de adaptación.

No obstante, restó importancia a este asunto, que era, en definitiva, el que había motivado la interpelación de Sainz Rodríguez. "Eso ya ha perdido actualidad", dijo Callejo, debido a que el "noventa y tantos por ciento de los casos", en el momento de producirse el debate, ya estaban "resueltos y liquidados". Por lo tanto, a juicio del ministro, en la adaptación no se había seguido perjuicio serio para nadie. Habida cuenta del cariz que estaba tomando el debate, el presidente del Consejo de Ministros, Primo de Rivera, pidió la palabra para, en una de sus personales y castizas intervenciones, tratar de relativizar la importancia del objeto del debate, respaldar públicamente al ministro de Instrucción Pública y dar por zanjado el asunto:

El tema no era para alterarse. Señores, todos los que somos padres de familia hemos pasado con protestas muy vivas por planes de estudio que, acaso equivocadamente, no nos parecían acertados ni lógicos, y por unos textos muy gruesos que costaban bastantes pesetas; y lo lamentábamos como un mal nacional; pero no era para traer aquí la cuestión en términos de que se dijera: ¡Cuestión nacional! (...). No; no había motivo para esto. Creo que ustedes se han excedido, y tal vez me he excedido yo más en la reprensión que hice en mi intervención. Si es así, quedamos en paz y saldada la cuenta. (Aplausos).

\section{A MOdo de EPÍlogo}

El Plan Callejo ha sido, probablemente, el más controvertido e impopular en el agitado itinerario histórico de la segunda enseñanza española. La dictadura de Primo de Rivera, en su conjunto, hizo un notable esfuerzo por aumentar y mejorar la red de institutos oficiales, así como por hacer llegar el bachillerato a un mayor número de estudiantes. También se trató de propiciar, conforme a la demanda de los tiempos, una mayor presencia de mujeres en la enseñanza secundaria. 
Aunque la división del Bachillerato en dos periodos, elemental y universitario, establecida por el Plan Callejo se concibió como una medida orientada a propiciar la extensión social de la segunda enseñanza, el único descenso de matrícula en la década, en términos cuantitativos, se produjo en el curso 1927-1928; precisamente como consecuencia del desencanto provocado por la entrada en vigor del Plan Callejo, así como por las ya comentadas dificultades de adaptación a la nueva normativa. Si bien durante el Directorio militar se produjo un descenso de la enseñanza colegiada, probablemente por el incremento de centros oficiales, a partir del curso 1924-25 se constató un aumento sostenido de la enseñanza privada.

Más allá de sus propios aciertos y errores, el singular descrédito del Plan Callejo se ocasionó por la enorme repercusión que tuvo su discusión en la Asamblea Nacional de la dictadura. Y no solo fue consecuencia de la eficacia parlamentaria de Sainz Rodríguez. También porque el asunto se debatió en la sesión inaugural, cuando muchas familias de la todavía minoritaria España instruida, de cuyos hijos se nutría la segunda enseñanza, estaban pendientes de las incidencias que acontecían en la recién estrenada institución política del primorriverismo.

El propio Sainz Rodríguez, de quien hasta entonces no se conocía mayor inclinación hacia los temas educativos que la derivada de su propia condición de catedrático de Literatura, fue designado, once años después, ministro de Educación Nacional del primer Gobierno de Franco, precisamente por la notoriedad de su actuación contra el Plan Callejo. También debieron influir las muestras de apoyo que recibió su intervención desde diversas organizaciones de padres y profesores. Es evidente que en esta intervención de Sainz Rodríguez en la Asamblea ya se vislumbraron las que serían líneas maestras de su futura Ley de Bases de la Enseñanza de 1938.

La evolución de la dictadura de Primo de Rivera, sobre todo durante el periodo del Directorio Civil, propició la irrupción en el panorama político de una nueva derecha, de corte antiliberal, que tuvo un papel relevante en el origen de movimientos posteriores como Acción Española y la CEDA, y estuvo presente en los distintos sectores que protagonizaron la vida política durante el régimen de Franco. 
De igual modo, pensamos, se configuraron durante la Dictadura dos modelos de Bachillerato que alternarían en la política educativa del franquismo, e incluso antes, hasta la Ley General de Educación de 1970.

El primero de ellos, un Bachillerato clásico, único, del llamado carácter formativo, basado en el método cíclico y orientado exclusivamente a la enseñanza superior universitaria. Este modelo inspiró, como es obvio, la Ley de Bases de Sainz Rodríguez de 1938, pero también estuvo en el proyecto de Elías Tormo durante el Gobierno de Berenguer, publicado en Gaceta de Madrid -no llegó a entrar en vigor- el 25 de agosto de 1930. Lo cierto es que el carácter selectivo del Plan 38, unido a la severidad del examen de Estado, así como la escasez del presupuesto nacional destinado a la Enseñanza Media en los difíciles años cuarenta, ocasionaron un preocupante estancamiento de la matrícula de este tramo educativo durante el periodo ministerial de Ibáñez Martín (1940-1951). Al entrar la década de los cincuenta la matrícula de Bachillerato no llegaba al $10 \%$ de la población en edad de cursarlo.

El segundo modelo, un Bachillerato ecléctico, dividido en dos periodos; uno elemental, de validez académica propia, concebido como continuación de la Primaria; y otro periodo superior, bifurcado en Ciencias y Letras, orientado a la enseñanza universitaria. Este modelo de bachillerato, que fue el establecido por el Plan Callejo, estaría presente en el anteproyecto de ley de Enseñanza Media de 1947 y sobre todo en la reforma de la Enseñanza Media de Ruiz-Giménez en 1953. Andando el tiempo, en el preámbulo de la ley para modificar la de Ordenación de la Enseñanza Media en cuanto a las pruebas de grado y madurez (Ley 24, 1963), se señalaba que la ley de Enseñanza Media de Ruiz-Giménez "había constituido un factor decisivo en la extensión de la Enseñanza Media por los diferentes estratos de la sociedad española", constatando que en apenas una década el número de estudiantes de Bachillerato había pasado de 150.000 a 600.000 . Otras consecuencias que se han atribuido (González Bertolín, 2015) a la implantación de la ley de 1953 son: la desactivación del conflicto entre los centros oficiales y no oficiales, la mejora notable en el interés por el quehacer pedagógico y la formación del profesorado, la consolidación de un grado académico básico a la edad de catorce años, la coordinación y convalidación de las diversas enseñanzas de grado medio y la creación de una inspección razonablemente seria y profesionalizada. En definitiva, se consiguió corregir el carácter elitista y 
selectivo del Plan 38 y lograr una mayor implantación del bachillerato, no solo incrementando el número de estudiantes en este tramo académico, sino propiciando la extensión social y territorial de la Enseñanza Media.

\section{BiBLIOGRAFÍA}

Álzaga, O. (1973). La primera democracia cristiana en España. Barcelona: Ariel.

Asamblea Nacional Consultiva (1927). Debate sobre la adaptación del nuevo Plan de Bachillerato. Madrid: Biblioteca del Congreso de los Diputados, 16-26.

AvilÉs, J. (2017). Un pálido reflejo del fascismo: la dictadura de Primo de Rivera en los informes diplomáticos italianos. Pasado y Memoria. Revista de Historia Contemporánea 20, 69-90.

Azaña, M. (23/02/1923). La Universidad y los Colegios, en OC, II (pp. 324325). Madrid: Centro de Estudios Políticos y Constitucionales,

Barba, D. (2001). La oposición durante el franquismo. La Democracia Cristiana. Madrid: Encuentro.

Barrio, A. (2004). La modernización de España (1917-1939). Política y sociedad. Madrid: Síntesis.

Ceprián, B. (1991). Del Consejo de instrucción Pública al Consejo Escolar del Estado. Origen y evolución. Madrid: UNED.

Cuenca, M. (2003). Catolicismo social y político en la España contemporánea 1870-2000. Madrid: Unión Editorial.

Fonck, B. (2010). Ortega y el poder bajo la Dictadura de Primo de Rivera en los inéditos del tomo VII de las Obras Completas. Revista de Estudios Orteguianos 20, 7-19.

GimÉNEZ, M. A. (2018). La representación política en España durante la dictadura de Primo de Rivera. Estudios Historia 31(64), 131-150.

Gómez-Navarro, J. L. (1991). El régimen de Primo de Rivera: reyes, dictaduras y dictadores. Madrid: Cátedra.

González Calleja, E. (2005). La España de Primo de Rivera. La modernización autoritaria 1923-1930. Madrid: Alianza. 
GonzÁlez Cuevas, P. (2005). El pensamiento político de la derecha española en el siglo XX. De la crisis de la restauración al Estado de los partidos. Madrid: Tecnos.

GonzÁlez Bertolín, A. (2015). De la Enseñanza Media de élite al Bachillerato del siglo xxI. Edetania 20, 101-115.

González Bertolín, A. y Sanz, R. (2018). "Excluyentes” y “comprensivos". Joaquín Ruiz-Giménez y los orígenes de la extensión de la Enseñanza Media en España. Educació i Història. Revista d'Història de la Educació 32, 89-113.

LeY 24/1963, sobre modificación de la Ley de Ordenación de la Enseñanza Media en cuanto a las pruebas de grado y madurez. BOE, núm. 55, 05/03/1963, 3747-3747.

LÓPEZ DE Í̃̃IGUEZ, J. (2015). Noventa años de historiografía sobre la dictadura de Primo de Rivera: un estado de la cuestión. Historiografía 10, 85-108.

López MARTín, R. (1994). Ideología y educación en la dictadura de Primo de Rivera I: Escuelas y Maestros. Valencia: Universitat de València.

Morales, D. (2018). El golpe de Estado de primo de Rivera a través de la prensa nacional. Un análisis comparativo. Revista Historia Autónoma 12, 171-190.

Morodo, R. (1980). Acción Española. Orígenes ideológicos del franquismo. Madrid: Tucar Ediciones.

Primo de Rivera, M. (14/04/1923). Manifiesto. $A B C, 1$.

Payne, S. (1984). El catolicismo español. Barcelona: Planeta.

Sainz Rodríguez, P. (1978). Testimonio y recuerdos. Barcelona: Planeta.

Tusell, J. (1974). Historia de la Democracia Cristiana en España I. Los antecedentes. La CEDA y la II República. Madrid: Edicursa. 